\title{
Analysis of Runoff into Reservoir Change Pattern and Causes in Fenhe Reservoir
}

\author{
Caihong Hu, Zhihua Zhang, Nan Li \\ Water Resources and Environmental Engineering Department, Zhengzhou University, Zhengzhou, China \\ Email: hucaihong@zzu.edu.cn
}

Received 8 June 2016; accepted 26 July 2016; published 29 July 2016

\begin{abstract}
Based on the 58 years monthly flow data (from 1956 to 2013) editing by Jingle hydrological station of Fen River and Shangjinyou station, data resources are used to analyze the annual and inter-annual changes from spatial and temporal scale by statistical methods, mainly annual spatial and temporal distribution, trend of inter-annual changes, cycle and mutation changes. The reasons of runoff into reservoir changes are deeply analyzed by annual precipitation data of catchments above Fenhe Reservoir 1956 to 2013 and the land and water reservation methods which are implemented recently. It shows that there is a significant decrease of the inter-annual run-off with main and second cycle periods, 23a and 13a respectively. Furthermore, it exists mutation point between 1970 and 1971 through runoff series. As for further analysis of the causes of Fenhe Reservoir runoff changes, it illustrates that the change of precipitation is the main reason the facilitate runoff changes. Also, the land and water reservation methods which are implemented in upstream of Fenhe Reservoir increase water storage capacity of soil, showing it non-ignorable effect to runoff changes.
\end{abstract}

\section{Keywords}

Annual Runoff, Trend, Cycle Period, Mutation, Analysis of the Cause of Runoff Change

\section{Introduction}

Fen River, the mother river of Shanxi Province and the second biggest tributary of Yellow River, has about $39826 \mathrm{~km}^{2}$ of catchment area with $709.9 \mathrm{~km}$ long and the volume of runoff is $2067 \mathrm{million} \cdot \mathrm{m}^{3}$, which is occupied $25.5 \%$ of the total area of Shanxi Province. It has 2250 million $\cdot \mathrm{m}^{3}$ of groundwater resources and 3358 million $\mathrm{m} 3$ water resources, occupying 27.2\% of total amount of water resources in Shanxi Province. Fenhe Reservoir, the biggest reservoir in Shanxi Province with $5268 \mathrm{~km}^{2}$ control catchment area locating in the upstream of Fen River, plays an important role in Taiyuan which is the capital of Shanxi Province, Jinzhong and Lvliang etc., mainly the barriers of flood defense and water reservation. With the implementing and development of Yellow River Diversion Project in Shanxi Province, Fenhe Reservoir also plays an important part in flood management through diversion from Yellow River, mainly defense and storage flood. To data, the continuous reduction of runoff into reservoir has constrained normal social and economy development of the catchment area, causing the reduction of downstream runoff sourcing from Yellow River and the ability of providing water of Yellow River. 
As the foundation of flood defense, hydro power and irrigation, changes of runoff can directly affect the degree of usage of reservoir water resources and its appropriate distribution. Thus, it is necessary to analyze the regular pattern and causes of runoff into reservoir changes in Fenhe Reservoir, which can provide theoretical support for optimal distribution and usage of water resources in reservoir and examples to explore answers of the runoff reduction of Yellow River. With the society and human activities development, climate and underlying surface of basin have changed gradually owing to human effect, influencing the characteristics of runoff changes. It shows the same situation to Fenhe Reservoir, attracting sizable scholars' attention and a large number of researches appeared, such as Caihong Hu and Jijun Wang [1] who analyzed the uneven distribution of annual runoff of the main control station locating in upstream of Fenhe Reservoir, which is based on the systematical analysis of annual uneven distribution index, Yujun Dang [2] who use statistical methods to analyze the change characteristics of upstream runoff change, Shifang Ren and Shuzhen Zhao [3] who researched the upstream runoff tendency of Fenhe Reservoirn during half century, Caihong Hu et al. [4] who analyzed the contribution of climate change and land and water reservation methods in Fenhe Reservoir to runoff of Fenhe Reservoir, and Fuhua Hao [5] who analyzed the changes of flow and sediment after lad and water reservation management in Fenhe Reservoir. Also, there are sizable researches to study the normal pattern and causes of runoff changes in different catchment [6]-[9].

\section{Data and Methodology}

\subsection{Data Background}

Fenhe Reservoir has three hydrological station Jingle $\left(2799 \mathrm{~km}^{2}\right)$, Shangjinyou $\left(1140 \mathrm{~km}^{2}\right)$ which together take up $75 \%$ of the catchment and Loufan which occupies the rest $25 \%$. Thus, owing to the large portion of areas (75\%), the monthly data of Jingle and Shangjinyou hydrological stations from 1956 to 2013 are employed to analyze spatial and temporal distribution of annual runoff into reservoir, inter-annual tendency, cycle period and mutation changes of runoff in Fenhe Reservoir. Precipitation data from 1956 to 2013 which are observed inn 32 gauging station within the catchment are employed to calculate precipitation of the catchment by arithmetic average.

\subsection{Methodology}

It will use uniformity coefficient [10] to analyze the uneven annual runoff distribution, followed by analysis of tendency and mutation of runoff into Fenhe Reservoir by M-K test method and Sliding T law method [11]-[13]. Also, Wavelet variance [14] is employed to analyze the periodical change inter-annual runoff. Tendency and mutation change will be used for analyzing runoff change in Fenhe Reservoir.

\section{Mutation Analysis of Runoff into Reservoir}

\subsection{Trend Variation}

According to the runoff data from 1956 to 2013 of Jingle station and Shangjingyou station which are the main water source control stations of Fenhe Reservoir, the multi-year (1956-2013) mean runoff into Fenhe Reservoir is 0.35 billion $\mathrm{m}^{3}$, the maximum runoff is $0.105 \mathrm{billion} \cdot \mathrm{m}^{3}$ which was recorded at 1967 and the minimum runoff is 0.1 billion $\cdot \mathrm{m}^{3}$ which was recorded at 2001, multi-year extreme ratio is 9.71. Figure $\mathbf{1}$ depicts that the variation trend of annual runoff.

It is clear that there exists a decreasing tendency of runoff into reservoir and runoff fell on average $5.63 \mathrm{~mm}$ each decade. According to the statistical data, the average value for these durations such as 1956-1967, 19681979, 1980-1991, 1992-2003 and 2004-2013 is 92.8., 70.9, 50.9, 53.6 and 68.2 respectively. As can be seen from Figure 1, the runoff increased a lot after 2005. However, when using the Mann-Kendall check method to test these data, the tendency test results $\mathrm{Z}$ value ( $\mathrm{Z}$ value is the absolute value of Mann-Kendall parameter) is -2.5893 which reflects that the runoff decreasing tendency is obviously.

\subsection{Mutability}

In order to test the hydrologic series mutability of the runoff into reservoir data, the running t-test of MannKendall check method has been used in this paper, the results can be seen from Figure 2. Figure 2 depicts that 


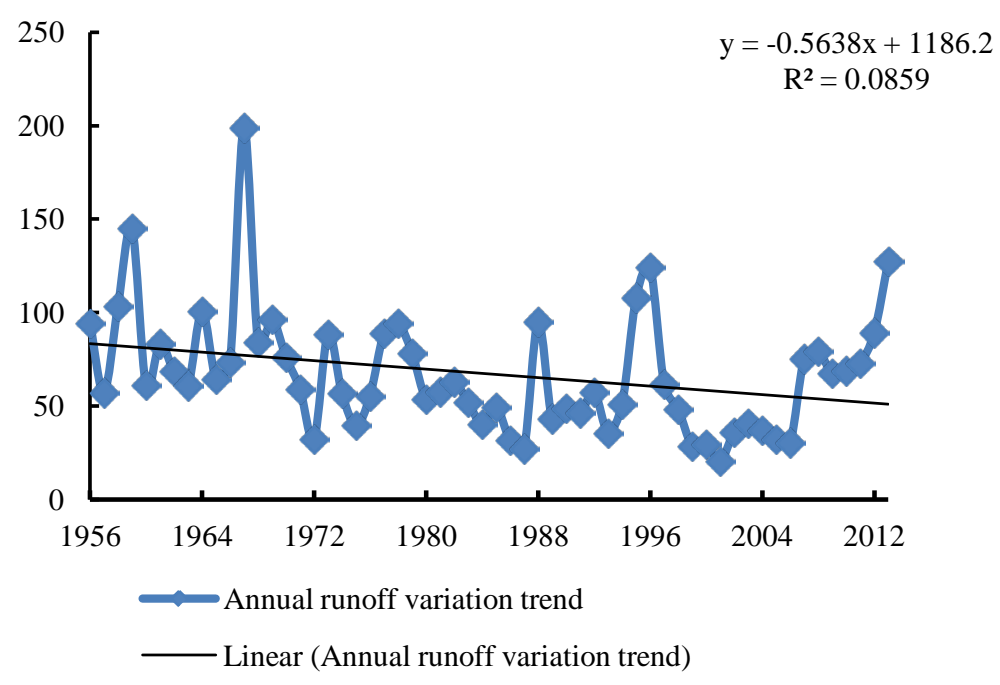

Figure 1. Variation trend of annual runoff.

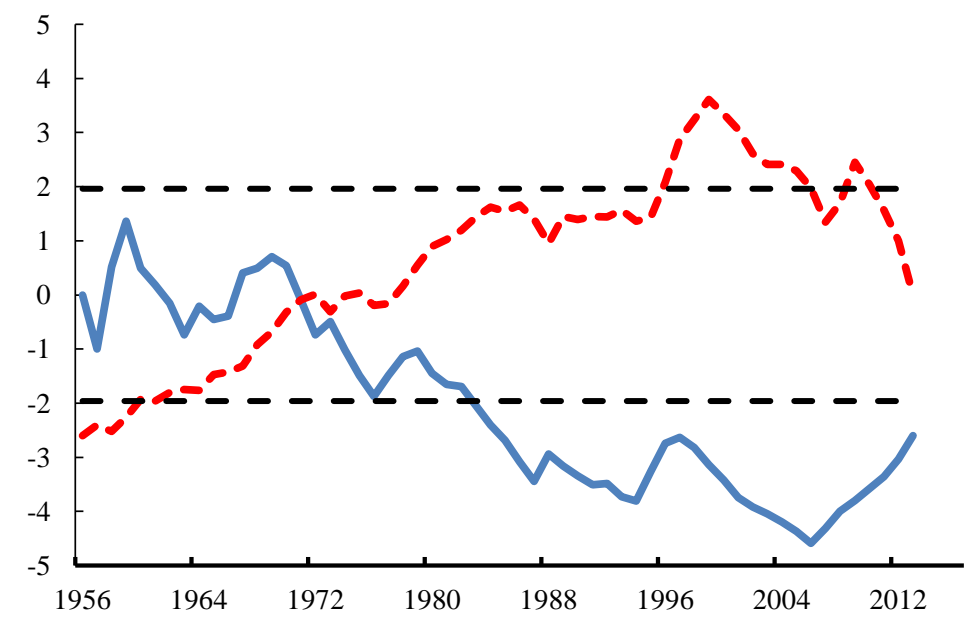

Figure 2. M-K test results analysis.

the runoff into reservoir has the clear mutability point, especially the trend has been declined between 1980 and 2006. In addition, the blue and red lines have a point of intersection between 1970 and 1971 which indicts that there has a mutability point among this time slot. In order to test the accuracy of these results, the running t-test has been used and the running t-test value is 3.6863 which beyond 2.7 (0.001), test results indicts that mutability is existence. In summary, the results of two test methods are accordance.

\subsection{Periodicity}

Figure 3 shows that the Wavelet variance of runoff into Fenhe reservoir series. The Wavelet variance can reflect the energy various with scale distribution, the peak of the Wavelet variance diagram is the main existence time scale of discharge series. The value stands for the size of one specific scale and reflects whether the accordance time scale periodicity is obviously. In other words, bigger wavelet variance value means more obvious periodicity. According to Figure 3, the runoff into reservoir has clear periodicity. There are two peaks among the time scale which divide the runoff series into primary and secondary periods. The two periods are 23a and 13a which illustrates the instability of annual runoff variation.

\subsection{Spatial and Temporal Distribution within the Year}

The Unevenness Coefficient also named as Variation Coefficient which is a reflection of to what degree can 
uneven distribution set as time series comprehensive index and can be used as analysis research of time series multiple qualities. In this paper, the Unevenness Coefficient is defined as the distribution level within one year. According to runoff into reservoir data, Jingle station is the Main stream control station which constitutes $54 \%$ $78 \%$ of the total runoff, so the distribution within one year degree of this station can stands for the whole runoff distribution level. Figure 4 depicts that the within one year distribution parameter changed year by year. The maximum Unevenness Coefficient is 1.802 at 1967 and minimum Unevenness Coefficient is 0.266 at 1989 which indicts that the uneven distribution coefficient level is relatively high in this two years. In addition, the Unevenness Coefficient fluctuates at 1 , the reason for that is this catchment is located at semi-arid region, runoff has been influenced severely by the underlying surface and those changes have a certain lag effect.

\section{Analysis of Runoff into Reservoir Variation Factors}

As the second largest tributary of Yellow river, Fenhe is located at North China Loess Plateau region, the whole catchment belongs to Shanxi province which is Semi-arid regions transition zone. Fenhe reservoir is located above the Fenhe, the runoff into reservoir is mainly river flow and river flow is a product of cooperation of both climate change and catchment underlying surface, so the runoff is not only can be influenced by human activities, but also be sensitivity of climate change degree. Under the climate change situation, rainfall in the direct

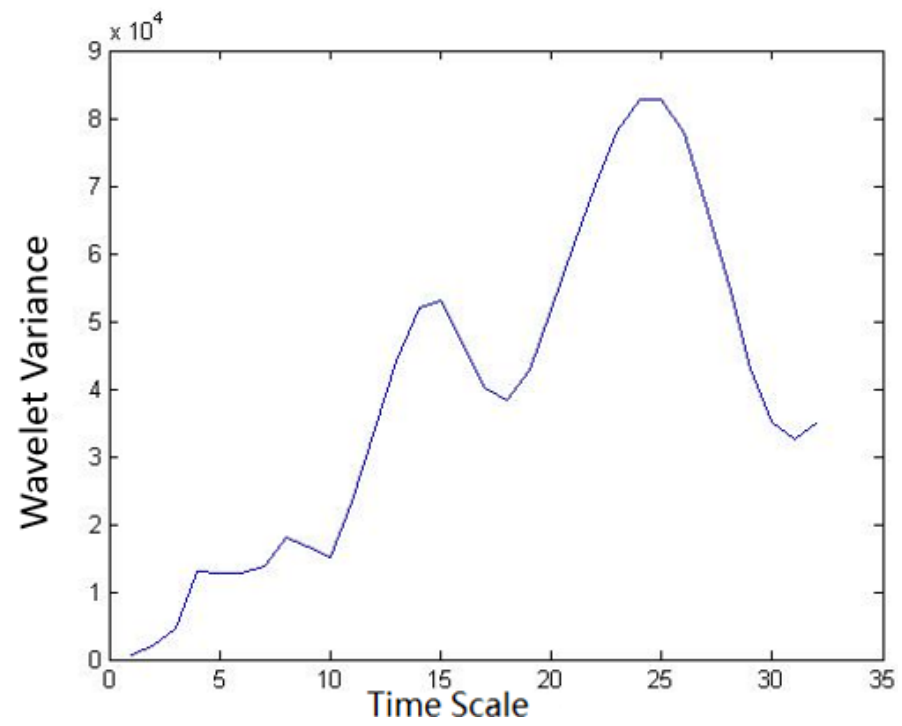

Figure 3. The wavelet variance diagram.

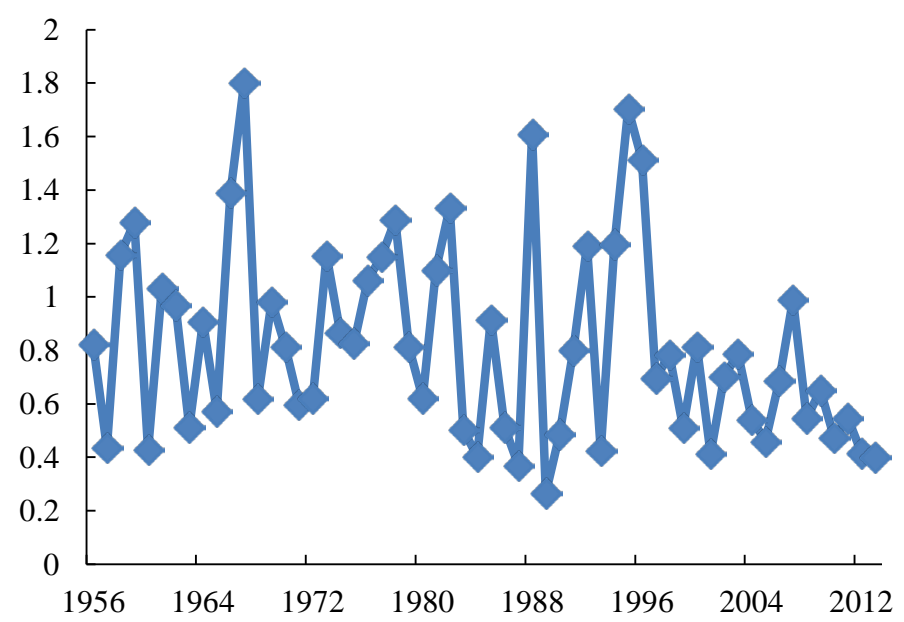

Figure 4. The within one year distribution parameter changed year by year. 
factor for the formation of runoff, hence the main reason for runoff into reservoir are rainfall various with climate change and underlying surface changed with human activities.

\subsection{Rainfall Impact Analysis}

According to the rainfall from the rain gauging stations of basin above Fenhe Reservoir from 1956 to 2013, obtained area rainfall by using arithmetic mean method, then analyzing the data and drawing the contrast figure of area rainfall and runoff trend (see Figure 5).

According to statistics and the results of Figure 4, the rainfall nearly decrease $8.11 \mathrm{~mm}$ every 10 years, and 1956-1967, 1968-1979, 1980-1991, 1992-2003 and 2004-2013 is 536.2, 500.9, 479.9, 537.1, 598.1 respectively. Annual rainfall sequence also tends to decrease, and the runoff have consistent trend with rainfall, but the decreasing trend of runoff is more significantly. Both of them began to increase from 80 to 90 years. Showing that runoff is decided by the formation of rainfall. However, Figure 3 shows, before the 1990s, the extent of the uneven distribution of runoff is more than after, indicating underlying surface conditions change under the effect of human activities also plays a non-negligible role in formation of runoff except rainfall.

\subsection{Analysis of the Measures Impact about Conservation of Water and Soil}

Measures of conservation of water and soil are mainly affected by changing the underlying surface of the basin, increasing water storage capacity of the soil to affect the formation of runoff. Humans changed the underlying surface of the basin and the area of the land use type by planting trees and grass, constructing of terraces, conceding the land to forestry and other measures of conservation of water and soil. In 1983, the upstream of Fenhe Reservoir in Shanxi Province has been listed as the focus of watershed management, the investment of conservation of water and soil increased from 600,000 yuan to 160 million yuan every year, and implemented small watershed management unit, from 1998 to 2008, conducted again the comprehensive control of water and soil erosion of a period of 20 years [15]. By the end of 2006, the cumulative save area of measures of conservation of water and soil of Fenhe Reservoir was 2.223 million $\mathrm{hm}^{2}$. After implementing the measures of conservation of water and soil, trends in rainfall and runoff storage is shown in Figure 6.

Figure 6 shows that the rainfall increasing trend is clearly higher than the runoff increasing trend. This is due to the late 1980s the water storage capacity of the soil was increased after implementing the measures of conservation of water and soil, the increment of runoff is less than the increment of rainfall. This explains that the impact of human activities on changing the underlying surface for runoff formation plays a non-negligible role.

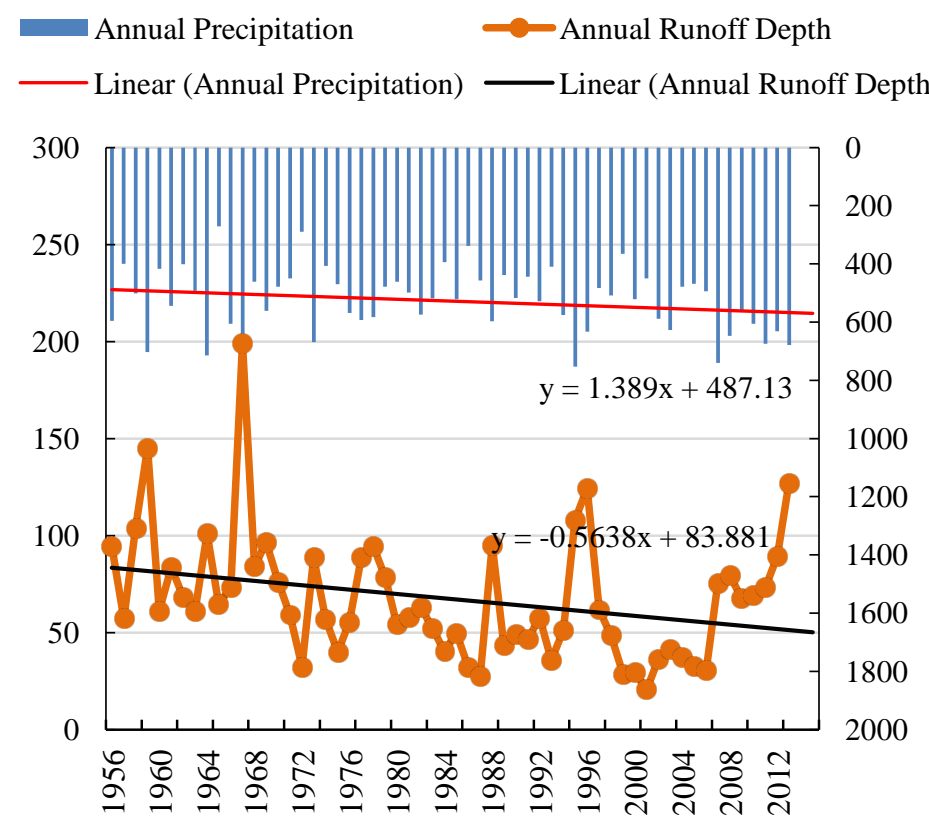

Figure 5. Rainfall and runoff change trend contrast. 


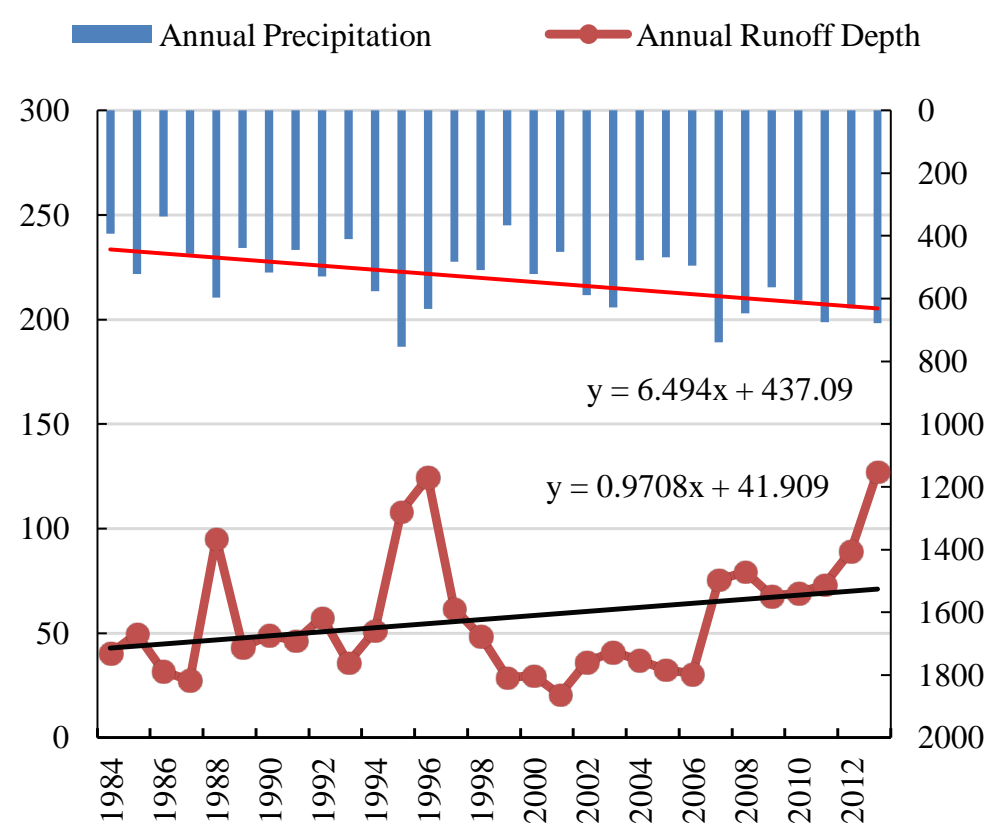

Figure 6. After the implementation of conservation measures of rainfall and runoff change trend contrast.

\section{Conclusions}

1) It is concluded that the decrease of the runoff series presents obvious trend and significant mutation, according to the incoming runoff data of Fen river reservoir from 1956 to 2013 with statistical method analysis of the trend of runoff series. But the runoff of series increased after 2005. Analysing the cycle of runoff series with the small polish difference analysis method, the primary and secondary cycles of incoming runoff sequence are obvious, the primary and secondary cycle is respectively 23a, 13a.

2) According to the precipitation station data above Fen river reservoir basin from 1956 to 2013 and cause analysis of the implementation of soil and water conservation measures on runoff variation law in Fen river basin in recent years. The results show that, rainfall is the main cause of the change of the incoming runoff of Fen river reservoir. In recent years, soil and water conservation measures of the Fen river upstream basin have improved soil water storage capacity in the basin, which plays a role that cannot be ignored that change the incoming runoff.

\section{References}

[1] Hu, C.H. and Wang. J.J. (2009) The Research of Watershed Runoff Year Distribution Schedule Change Law of Fen River Reservoir Upstream. Journal of Arid Land Resources and Environment, 6, 85-90.

[2] Dang, Y.J. (2015) The Variation Characteristics Analysis of Fenhe Upstream Runoff. China Rural Water and Hydropower, 9, 31-33.

[3] Ren, S.F. and Zhao. S.Z. (2012) The Runoff Trend Analysis of Fenhe Reservoir Upstream. Yellow River, 3, 17-18.

[4] Hu, C.H., Guan, X .J., Wu, Z.N., et al. (2011) Analysis for Contribution or Soil and Water Conservation and Climate Runoff in the Upper of Fenhe Reservation. Journal of Soil and Water Conservation, 25, 12-16.

[5] Hao, F.H. (2009) Analysis on Rub-Off Variation and Sediment Reduction for Water and Soil Conservation of Fenhe River Basin. Water Resources and Hydropower Engineering, 5, 61-63.

[6] Wei, L.X., Yu, H. Wang, Z.Y., et al. (2014) Characteristics and Genesis Analysis of Variation of Poyang Lake Flow into Yangtze River. Yangtze River, 23, 88-91.

[7] Da, C.J., Huang, Q. and Wang, Y.M. (2012) Analysis of Runoff Evolution law of Tarim River Basin. Journal of Water Resources Research, 1, 353-358. http://dx.doi.org/10.12677/JWRR.2012.15054

[8] Zhang, Q., Xiao, C.L., Zhu, Y.P., et al. (2013) Analysis of Temporal and Spatial Variation Characteristics of Runoff and Its Causes in Jilin Province. Transactions of the Chinese Society of Agricultural Engineering, 7, 53-57. 
[9] Feng, J.Y., Ke, X.X. and Yao, Z.Z. (2000) Long-Term Evolution of the Upstream of the Yellow River Runoff. Yellow River, 22, 40-42.

[10] Lu, J.Y., Wang, X.Q., Wang, X.B., et al. (2015) Measurement Index of Intra-Annual Runoff Distribution Nonuniformity and Its Application. Water Power, 11, 24-28.

[11] Chen, C.C., Xie, G.D. and Zhen, L. (2007) Characters of Precipitation Variation in Jinghe Watershed. Resources Science, 29, 172-177.

[12] Lu, A.G. and Wang Y. (2012) Analysis on Temperature and Precipitation Variations of Yan'an in the Recent 60 Years. Journal of Arid Land Resources and Environment, 26, 60-62.

[13] Foster, G.R, Huggins, L.F. and Meyer, L.D. (1984) A Laboratory Study of Rill Hydraulics II: Shear stress Relationship. Transaction of the ASAE, 27, 797-804.

[14] Wang, W.S., Ding, J. and Xiang, H.L. (2002) Application and Prospect of Wavelet Analysis in Hydrology. Advances in Water Science, 13, 515-520.

[15] Zhang, J. (2005) Great Achievement Gained in Comprehensive Management of Soil and Water Conservation in Upper Stream of Fenhe River. Soil and Water Conservation in China, 10, 10-18.

\section{Submit or recommend next manuscript to SCIRP and we will provide best service for you:}

Accepting pre-submission inquiries through Email, Facebook, LinkedIn, Twitter, etc.

A wide selection of journals (inclusive of 9 subjects, more than 200 journals)

Providing 24-hour high-quality service

User-friendly online submission system

Fair and swift peer-review system

Efficient typesetting and proofreading procedure

Display of the result of downloads and visits, as well as the number of cited articles

Maximum dissemination of your research work

Submit your manuscript at: http://papersubmission.scirp.org/ 